\title{
BRINCANDO NO HOSPITAL: A EXPERIÊNCIA DOS ENFERMEIROS COM O USO DO BRINQUEDO TERAPÊUTICO EM UNIDADES PEDIÁTRICAS
}

\author{
Fabiane de Amorim Almeida1, Lidia Souza dos Reis Silva1 e Carolline Machado de Miranda1 \\ 1Faculdade Israelita de Ciências da Saúde Albert Einstein, Brasil. fabi.almeida17@outlook.com; lidiasrs@einstein.br; \\ carolline.miranda@einstein.br
}

\begin{abstract}
Resumo. Introdução: O estudo investiga sobre a experiência do enfermeiro com o uso do BT na prática, buscando delinear os fatores que influenciam no desenvolvimento desta atividade, como etapa inicial da implementação rotineira do BT em unidades de pediatria. Objetivo: Compreender a percepção do enfermeiro sobre o uso do BT, a partir das experiências vivenciadas por ele ao cuidar da criança no hospital. Método: Estudo descritivo, de abordagem qualitativa, desenvolvida nas unidades pediátrica e de terapia intensiva pediátrica de um hospital de São Paulo, Brasil. A amostra constituiu-se 21 enfermeiros que participaram de uma entrevista semi-estruturada e seus relatos foram analisados por meio da Análise Temática de Conteúdo. Resultados: Quatro categorias emergiram dos discursos: Resgatando o primeiro contato com o BT; Apesar de complexo e trabalhoso no início, o uso do BT é percebido como uma experiência positiva; Enfrentando dificuldades para realizar o BT na prática; Entendendo que o BT deve ser usado desde a admissão da criança no hospital. Considerações finais: O contato com o BT durante a trajetória profissional leva o enfermeiro a reconhecer essa experiência como positiva, apesar das dificuldades enfrentadas, entendendo que para cuidar da criança precisa brincar com ela desde que chega ao hospital.
\end{abstract}

Palavras-chave: Jogos e Brinquedos; Criança Hospitalizada; Admissão do Paciente; Enfermagem Pediátrica; Humanização da Assistência.

\section{PLAYING AT THE HOSPITAL: NURSES' EXPERIENCE WITH THE USE OF BT IN PEDIATRIC UNITS}

\begin{abstract}
Introduction: The study investigates the nurse's experience with the use of BT in practice, seeking to outline the factors that influence the development of this activity, as the initial stage of the routine implementation of BT in pediatric units. Objective: To understand the nurse's perception about the use of BT, from the experiences he experienced when caring for the child in the hospital. Method: Descriptive study with a qualitative approach, developed in the pediatric and pediatric intensive care units of a hospital in São Paulo, Brazil. The sample consisted of 21 nurses who participated in a semi-structured interview and their reports were analysed using the Thematic Content Analysis. Results: Four categories emerged from the speeches: Rescuing the first contact with BT; Although complex and laborious at first, the use of BT is perceived as a positive experience; Facing difficulties to carry out BT in practice; Understanding that BT should be used since the child's admission to the hospital. Final considerations: The contact with BT during the professional trajectory leads the nurse to recognize this experience as positive, despite the difficulties faced, understanding that to take care of the child, he needs to play with him since he arrives at the hospital.
\end{abstract}

Keywords: Play and Playthings; Hospitalized Child; Patient Admission; Pediatric Nursing; Humanization of Assistance.

\section{INTRODUÇÃO}

A criança hospitalizada tem dificuldade para entender o que se passa com ela e o uso do brinquedo terapêutico (BT) pode auxiliá-la a compreender a necessidade da internação, 
vivenciando este momento mais tranquilamente (Caleffi, Rocha, Anders, Souza, Burciaga, \& Serapião, 2016).

O BT é um dos tipos de brincadeira utilizada frequentemente pelo enfermeiro, constituindose em uma atividade estruturada, que possibilita à criança aliviar a ansiedade causada por experiências atípicas para a idade, como a hospitalização entre outras. Estas experiências costumam ser ameaçadoras e requerem mais do que recreação para resolver a angústia associada. Assim, o BT deve ser usado sempre que a criança tiver dificuldade em lidar e compreender uma situação difícil vivenciada por ela (Maia, Ribeiro, \& Borba, 2011).

Um estudo analisou a contribuição do BT estruturado em um Modelo de Cuidado de Enfermagem à criança hospitalizada apontando que, quando ela brinca, o ambiente hospitalar e os profissionais passam a ser vistos de maneira menos negativa, amenizando os prejuízos de uma hospitalização mal vivenciada (Caleffi, Rocha, Anders, Souza, Burciaga, \& Serapião, 2016).

As crianças que têm oportunidade de brincar com materiais hospitalares, realizando os procedimentos a que são submetidas, conseguem esclarecer dúvidas e curiosidades, entendendo a necessidade de realizá-los e reduzindo seus medos (Caleffi, Rocha, Anders, Souza, Burciaga, \& Serapião, 2016).

Estudos apontam que o BT possui uma ação potencialmente terapêutica no ambiente hospitalar e em outros contextos de saúde. Quando aplicado de forma efetiva, auxilia a equipe de saúde ao estimular a cooperação da criança na realização de procedimentos invasivos e dolorosos, além de promover uma rápida recuperação (Barroso, Santos, Santos, Nunes, \& Lucas, 2020; La Banca, Ribeiro, Freitas, Freitas, Nascimento, Monteiro, \& et al, 2019; Pontes, Tabet, Folkmann, Cunha, \& Almeida, 2015; Paladino, Carvalho, \& Almeida, 2014; Maia, Ribeiro, \& Borba, 2011).

Um estudo desenvolvido com crianças de uma unidade de terapia intensiva pediátrica brasileira enfatiza o predomínio de comportamentos positivos na sessão de BT, como não chorar, não demostrar medo, manipular brinquedos, dramatizar procedimentos e o desejo de continuar a brincadeira após o seu término, evidenciando prazer e satisfação ao brincar (Fontes, Oliveira, \& Toso, 2017). 
Apesar das vantagens e benefícios do seu uso em instituições de saúde, ainda é pouco empregado na prática, em função de algumas dificuldades apontadas pelos profissionais de saúde, que se sobrepõem às vantagens, comprometendo sua implementação sistemática na prática assistencial (Oliveira, Maia, Borba, \& Ribeiro, 2015).

Entendendo a importância do BT no cuidado à criança hospitalizada e estando sensibilizadas para as dificuldades enfrentadas pelos profissionais para inseri-lo em seu cotidiano, as autoras realizaram este estudo, partindo da seguinte questão norteadora: como é para o enfermeiro usar o BT ao cuidar da criança hospitalizada na sua prática diária?

\section{OBJETIVO}

Compreender a experiência do enfermeiro em relação ao uso do BT no cuidado à criança hospitalizada em seu cotidiano profissional.

\section{METODOLOGIA}

Trata-se de uma pesquisa descritiva, de abordagem qualitativa, desenvolvida nas unidades de pediatria e terapia intensiva pediátrica (UTI-P) de um hospital do município de São Paulo, Brasil.

A amostra constituiu-se de 21 enfermeiros que atuavam nas referidas unidades e tiveram contato com o BT na prática ou acompanharam a sua utilização por outro profissional, concordando em participar da pesquisa. Foram excluídos aqueles afastados por licença ou férias no período de coleta dos dados.

A maioria dos enfermeiros era do sexo feminino (20;95,2\%), com idade entre 24 e 58 anos (média $=33,2$ anos) e tempo de trabalho na unidade atual entre menos de um ano a 29 anos (média = 7 anos). Quase todos possuíam especialização (20; 95,2\%), com destaque para a área de terapia intensiva pediátrica, pediatria e neonatologia, sendo que apenas dois enfermeiros possuíam mestrado.

Em relação ao uso do BT, a maioria dos enfermeiros o utiliza ocasionalmente $(11 ; 52,4 \%)$, sendo que quatro o utilizam raramente ou nunca o utilizaram $(19,0 \%)$ e dois, frequentemente $(9,2 \%)$. A maioria deles teve contato prévio com o BT antes de trabalhar nesta unidade (18; $85,7 \%)$ 
Por ser um estudo qualitativo, o número de participantes foi definido no decorrer da coleta de dados, encerrando-se a inclusão de novos participantes quando as informações obtidas possibilitaram compreender a situação estudada (Polit \& Beck, 2011).

Os enfermeiros participaram de uma entrevista semiestruturada, conduzida a partir de um roteiro, elaborado pelas autoras da pesquisa, com os seguintes itens: perfil dos entrevistados e rotina de uso do BT na prática; perguntas norteadoras sobre a experiência do enfermeiro com o uso do BT na prática ao cuidar da criança no hospital. A entrevista foi gravada por meio de dispositivo de áudio, possibilitando a transcrição literal dos discursos para posterior análise dos dados.

Os enfermeiros foram entrevistados no período de trabalho, conforme sua disponibilidade. Inicialmente, era explicado sobre a pesquisa e em que consistia sua participação, apresentando o Termo de Consentimento Livre e Esclarecido, a ser assinado, se concordassem em participar do estudo.

Os dados foram coletados em 2019, após aprovação do projeto de pesquisa pelo Comitê de Ética em Pesquisa do Hospital Israelita Albert Einstein (número do parecer: 3.242.024), conforme a Resolução n 466, de 12/12/2012 (Ministério da Sáude, 2013).

Para analisar os dados, utilizou-se a Análise Temática de Conteúdo, que se constitui em um conjunto de estratégias de análise de comunicação utilizado para identificar, a partir de procedimentos sistemáticos e objetivos, o que é dito acerca de determinado tema (Bardin, 2011).

Na primeira etapa, procedeu-se uma primeira leitura mais abrangente das transcrições das entrevistas, buscando resgatar uma perceção inicial do conteúdo. Na etapa seguinte, leituras sucessivas foram realizadas, com o intuito de destacar as frases significativas do texto, que foram grifadas. Os trechos destacados foram codificados e, posteriormente, agrupados para constituir as categorias, de forma a apresentar o fenômeno estudado (Bardin, 2011).

No processo de categorização, inicialmente os trechos selecionados foram agrupados, considerando as diferenças temáticas que emergiram. Num segundo momento, os trechos passaram a ser agrupados por similaridade de conteúdo a categorias já existentes. Finalmente, elaborou-se a síntese dos discursos, a partir da aproximação dos dados 
empíricos da realidade aos pressupostos teóricos (Bardin, 2011). Destaca-se que este é um estudo mais amplo e, neste artigo, será apresentado parte dos resultados, sob a forma de 4 categorias temáticas.

\section{RESULTADOS}

A reflexão, por parte dos enfermeiros, a cerca das experiências vivenciadas com o uso do BT é revelada por meio das categorias apresentadas a seguir. A descrição da análise dos dados é acompanhada por trechos das entrevistas com os profissionais, identificados por meio de cores, escolhidas por eles próprios, como forma de garantir o sigilo de suas identidades.

\subsection{Resgatando o primeiro contato com o BT}

Alguns enfermeiros relataram que o primeiro contato aconteceu durante o curso de graduação ou pós-graduação. Evidencia-se nos discursos, o papel motivador do docente e de enfermeiros assistencial, sensibilizando os novos profissionais para a inclusão do BT no cuidado à criança.

Na faculdade, eu tive contato (com o BT)... bem pouco... em "Saúde da criança" (disciplina). [...] eu percebi que foi um assunto muito místico para enfermagem... como algo que não tinha sentido... que seria para fazer perder tempo. Na pós-graduação, eu tive um contato maior [...]. Tive oportunidade de aplicar (o BT) algumas vezes e vi o quanto é positivo. (royal)

Na minha formação, eu vim da U. (instituição de ensino onde se graduou). Lá, tem um grupo forte, que é da minha época. Era a professora $C$. e a $R$. que fazia um brinquedo. Mas quando eu estava lá, você sabe, se é envolvida com mil coisas. Não me peguei ao BT, até porque, quando eu estava na graduação, eu estava em dúvida, ainda, se eu ia querer geriatria ou pediatria. Foi só no último ano, que eu decidi. Aí, quando eu me formei... lá na pediatria, lá do hospital..., tinha a enfermeira G., na época, que ainda está lá até hoje. (pink)

Embora todos os entrevistados tivessem algum conhecimento sobre o BT, para alguns deles, o primeiro contato ocorreu na prática profissional, seja na unidade em que atuam no momento ou em experiências anteriores de trabalho. 
No hospital público que eu trabalhava, foi o primeiro momento que a gente...que eu tive contato (com o BT). (rosa)

Aqui (na instituição), foi o primeiro lugar (que apliquei o BT). [...] Na minha formação acadêmica, não foi falado nada disso. Eu conheci só na pós (pós-graduação). (bege)

Eu comecei a fazer o BT aqui na instituição. Nos outros serviços que eu trabalhei, a gente não trabalhava com BT. (prata)

\subsection{Apesar de parecer complexo e trabalhoso no início, o uso do BT é percebido como uma experiência positiva}

O enfermeiro reconhece que a realização da sessão de BT é trabalhosa e complexa em um primeiro momento, às vezes, por falta de conhecimento, revelando-se uma estratégia facilitadora para as demandas assistenciais futuras e reduzindo o tempo gasto na realização de procedimentos com a criança.

Achava um pouco de perda de tempo, até que eu fiz o primeiro (BT) com a primeira criança. Porque aí, eu vi que a gente realmente perde os dez minutos, mas depois ganha duas, três, quatro horas na assistência. Porque fica muito mais fácil. (preto)

O ganho que a gente tem com as crianças aqui, que ficam internadas principalmente (em internações) de longa duração, é muito válido. Tanto para a gente, mas principalmente para criança [...] Difícil...que a gente acha que... nossa, que não vai dar certo... de entrar no quarto da criança e ela esgoelar... e isso ser resolvido (com o BT), mesmo que a longo prazo. (branco)

Eu não fazia por falta de conhecimento e por falta de conhecer os benefícios que isso trazia, entendeu? Eu percebi que agora, depois de um tempo trabalhando na Pediatria e vendo o benefício que isso traz... (verde claro)

Muitas foram as experiências positivas relatadas pelo enfermeiro com o uso do BT, destacando-se o momento de abordagem da criança para examiná-la ou realizar procedimentos de enfermagem.

Se ela normalmente está muito agitada, não quer deixar... a gente leva uma boneca, leva aquele "esteto" (estetoscópio de brinquedo utilizado na sessão de BT) e aí, faz primeiro no brinquedo, [...] ela vai deixando a gente examinar ela com mais facilidade. (azul claro) 
O BT em si, (eu uso) raramente, mas a gente sempre pega... Sempre que possível, que tem algum brinquedo próximo, eu utilizo. Então, antes de examinar uma criança e ela tá com a boneca lá (brinquedo da própria criança), ela examina a boneca... É uma forma de fazer um BT, mas não aquele BT (refere-se à sessão do BT de forma estruturada). (cinza)

Para o enfermeiro, ficou clara a mudança de comportamento da criança após a realização do BT, que se torna mais tranquila, colaborando com os procedimentos.

Cuidei de um menininho que [...] entrava no quarto e ele: ããããh (imita choro da criança). Chorando o tempo todo... Tinha um dreno de tórax... a gente não sabia direito interpretar o que estava acontecendo. Eu falei com a C... (enfermeira da unidade): vê se consegue fazer BT com essa criança. Olha, no outro plantão, te juro, era outra criança... outra! [...] Ele mudou muito o comportamento. É lógico que ainda assustado, mas, assim, não tinha aquele comportamento o tempo todo, juro! (vermelho)

Sempre que a gente entrava no quarto, ela (a criança) chorava muito e aí, a gente começou a fazer BT com ela. No mesmo dia, a gente viu o resultado. Eu entrei e fiz (o BT). Ensinei ela a limpar o clave (dispositivo usado no acesso venoso), ensinei ela a fazer a medicação e tudo mais. E na próxima medicação que eu já fui administrar, ela já me ajudou a limpar o "clave". (preto)

O enfermeiro destaca a participação da família na sessão de BT, evidenciando o seu potencial para integrá-la ainda mais no cuidado à criança. Quando o familiar percebe que a brincadeira facilita a realização dos procedimentos com a criança, passa a confiar na equipe, estabelecendo uma relação de confiança com os profissionais.

Se você conseguir conquistar os pais, você já facilita o seu trabalho com a criança. Porque eles também vão te ajudar nessa brincadeira (o BT). (azul)

\subsection{Enfrentando dificuldades para realizar o BT na prática}

Sob o ponto de vista do enfermeiro, alguns fatores dificultam a implementação sistemática do BT, como: desconhecimento sobre este tipo de brincadeira e falta de capacitação dos enfermeiros para utilizá-lo na prática; desvalorização por parte de outros profissionais da equipe, que não respeitam a aplicação do BT; tempo insuficiente devido à demanda aumentada de atividades administrativas, burocráticas e assistenciais na unidade. 
Às vezes, acaba não sendo possível, pela demanda assistencial que a gente tem, né! [...] (prata)

Os profissionais ainda têm muita resistência de usar. [...] (vinho)

Vejo que aqui na instituição, a gente tem um pouco mais de foco com isso (o BT)... só que não é tão bem aproveitado. Eu acho que as pessoas poderiam ser um pouquinho mais inseridas e treinadas para fazer isso. [...] Eu sinto que, às vezes, é um pouco falho. Que a gente sabe que tem um brinquedo aqui... que a gente poderia colocar já no começo (desde a admissão), antes de fazer o procedimento. E a gente acaba recorrendo a esse recurso na hora que a criança já tem uma barreira de resistência. (cinza)

Destaca-se, ainda, que o enfermeiro do período noturno considera o horário inoportuno para realizar esta atividade. Enfermeiros da UTI também consideram que, devido à alta complexidade de cuidado de seus pacientes, têm dificuldade para utilizar o BT, mesmo reconhecendo sua importância. Por vezes, não se sentem tão preparados. Além do mais, ressaltam que nem sempre conseguem fazer o BT quando a criança chega a unidade e, depois, ela já foi submetida a procedimentos dolorosos sem preparo prévio com 0 brinquedo.

Nem sempre a gente consegue (fazer o BT à noite), porque as crianças já estão dormindo. (roxo)

Eu queria usar sempre... O quase nunca, é por causa da falta de tempo mesmo. Principalmente quando a gente está aqui na UTI [...] trabalhei muito tempo em uma UTI de alta complexidade, que não dava para fazer esse tipo de trabalho por conta da condição clínica dos pacientes... estarem sedados, em estado grave... (verde claro)

Aqui na UTI, às vezes, a criança não chega, assim, ééé...ela não chega numa situação que dá para aplicar o brinquedo. [...] Ela chega, e não dá para brincar. [...] Então, às vezes, você tem um pouquinho mais de atraso em aplicar o brinquedo e, principalmente, à noite [...] Então, às vezes, na admissão, durante a noite e na UTI, fica mais dificultoso, por conta disso... horário e o setor. [...] É assim.. .Aí, admitiu na madrugada e não conseguiu, então vai conseguir só durante o dia... Ou então, a criança chegou muito ruim, mais instável, conseguiu ajeitar ela um pouquinho durante a noite [...] a criança tá melhor, tá reclamando... aí, agora, vai aplicar o brinquedo. Só que ela já foi picada, já ficou no alto fluxo aqui. Já veio, já aspirou um monte, 
oitocentas e cinquenta pessoas já passaram, já viram examinaram a criança) ... mil pessoas já mexeram com ela, que ela não sabia... ela não queria. Ninguém pediu autorização dela e agora que vão introduzir o brinquedo, mas é que agora foi a situação que permitiu. (laranja)

Então aqui (na UTIP), a gente acaba focando mais em outras coisas. Lá (na pediatria), tem mais tempo para isso, porque a demanda é outra. Aqui, o enfermeiro é muito assistencial. O tempo inteiro é curativo... é isso... é aquilo. E tem os problemas para resolver... Então, às vezes, não é nem... às vezes, por falta de dedicação, talvez... não sei. De deixar um tempo para isso... Você acaba não fazendo. Você foca nas coisas de UTI, por isso que fica meio... se for parar para analisar, às vezes, soa como falta de vontade... talvez, de fazer (o BT), se for parar para pensar. Mas eu acho que, por ser complexidade diferente, tipo, você pega uma criança super grave, como você vai fazer o brinquedo, sendo que você tem tantas coisas para olhar ali dentro? [...]Então, o boneco acaba sendo a última coisa que você vai pensar. (turquesa)

\subsection{Entendendo que o BT deve ser usado desde a admissão da criança no hospital}

O enfermeiro entende que o emprego de BT deve ocorrer desde a admissão da criança na instituição e apontam a falta de tempo e a organização da rotina por parte da equipe para aplicar o BT nesse momento. Vislumbram, todavia, a possibilidade de fortalecer esta prática num futuro próximo.

Eu acho que faria toda a diferença no momento da admissão, porque a criança está vindo para um lugar que ela não conhece, ela não sabe o que vai acontecer...É pessoa chegando e pegando nela... Se houvesse tempo hábil ou se a equipe se organizasse... pra aplicar o BT na admissão, eu acho que isso minimizaria os traumas durante toda a internação. (marrom)

Sim, acho que ajuda (fazer o BT na admissão), principalmente se você começar a empregar logo no primeiro contato que você tenha... por exemplo, a fazer sinais vitais, entendeu? Você leva o boneco já... junto. Porque ela vai se familiarizando...não fica aquela coisa de só momento da tensão, entendeu? Acho que talvez seja melhor aproveitado. (rosa)

Então, se isso (uso do BT) vem desde a admissão para a gente... a gente trabalha muito mais tranquilo... as coisas fluem... a criança muito mais colaborativa... E fora os 
traumas que você não tá deixando...você tá deixando de introduzir traumas na assistência dessa criança. (dourado)

\section{DISCUSSÃO}

Os resultados permitiram ressaltar a importância que os enfermeiros atribuem ao uso do BT no hospital e os benefícios apontados são condizentes com os que vêm sendo enfatizado na literatura (Oliveira, Maia, Borba, \& Ribeiro, 2015; Marques, Silva, Cruz, \& Souza, 2015; Maia, Ribeiro, \& Borba, 2011).

Estudos revelam os inúmeros benefícios vivenciados por enfermeiros que utilizam o BT de forma sistemática na assistência de enfermagem com a criança, como: ajudá-la a compreender melhor a situação e promover seu bem-estar; acalmar e minimizar seu medo, estresse e ansiedade; favorecer o seu desenvolvimento e a socialização; formar vínculo e estreitar a relação com ela e sua família; propiciar a sensação de gratificação e realização para os profissionais envolvidos, além de humanizar o cuidado prestado (Oliveira, Maia, Borba, \& Ribeiro, 2015; Marques, Silva, Cruz, \& Souza, 2015; Maia, Ribeiro, \& Borba, 2011).

Os enfermeiros do presente estudo que afirmaram usar o BT, relatam que o utilizam principalmente quando têm dificuldade para abordar a criança e realizar os procedimentos. Resultados semelhantes quanto à reflexão dos enfermeiros sobre suas experiências com o uso BT foram apontadas no estudo realizado em um hospital infantil de São Paulo (Marques, Silva, Cruz, \& Souza, 2015)

Os profissionais entrevistados entendem, também, que a participação da família é importante, percebendo que os pais se sentem satisfeitos com este tipo de atendimento com brinquedo, ao identificarem que seus filhos apresentam mudanças de comportamento, aceitando melhor os procedimentos realizados e colaborando mais com toda equipe, estreitando, assim, a relação da família com os profissionais.

A família é percebida pela criança como fonte de segurança, devendo, portanto, ser inserida na assistência de enfermagem, participando, inclusive, das sessões de BT. Essa prática contribui para que a criança fique mais tranquila, tornando-se mais participativa nos cuidados (Caleffi, Rocha, Anders, Souza, Burciaga, \& Serapião, 2016).

Os enfermeiros entrevistados também relatam um sentimento de valorização e motivação no trabalho, quando percebem o reconhecimento dos familiares. Estudos refletem essa mesma 
realidade e apontam a participação da família como sendo importante e benéfica na aplicação do BT. Os enfermeiros reconhecem os familiares como facilitadores na comunicação e interação entre eles e a criança, apoiando a participação da família na sessão de BT (Maia, Ribeiro, \& Borba, 2011).

Ao começar a usar o BT na prática, os enfermeiros do presente estudo relataram que passaram a identificar inúmeros benefícios que antes não vislumbravam. O sentimento de descrença na efetividade do BT foi algo bastante ressaltado por eles também, relacionado à pouca experiência que possuíam, por serem recém-formados e o tema ter sido ser pouco explorado durante a graduação.

A Resolução do Conselho Federal de Enfermagem (COFEN) n. 546/2017 afirma que compete à equipe de enfermagem que atua na área pediátrica, a utilização da técnica do brinquedo/BT, na assistência à criança hospitalizada e sua família (Conselho Federal de Enfermagem, 2017).

A abordagem do conteúdo sobre brinquedo/BT nos cursos de graduação é uma recomendação do Conselho Regional de Enfermagem de São Paulo, que emitiu parecer favorável à sua utilização como um instrumento da assistência de enfermagem, recomendando que seja obrigatória a inclusão desta temática na grade curricular dos cursos de graduação em Enfermagem (Conselho Federal de Enfermagem, 2004).

Todavia, nem sempre a temática do BT é contemplada de maneira efetiva durante este período de formação acadêmica, uma vez que depende do valor atribuído pelo docente ao BT no ensino do cuidado à criança (Maia, Ohara, \& Ribeiro, 2019).

O Grupo de Estudos do Brinquedo (GEBRINq) é um grupo multidisciplinar e interinstitucional, credenciado pelo Conselho Nacional de Pesquisa (CNPq), que se propõe a aprofundar o estudo e realizar pesquisas sobre o ensino e prática do Brinquedo/ BT na assistência à criança e família, contribuindo para a capacitação de profissionais em diferentes regiões do Brasil.

A literatura aponta a necessidade de se fazer uma reflexão sobre o ensino do BT nos cursos de graduação em enfermagem, de modo que a abordagem deste assunto seja garantida no currículo do graduando, com o envolvimento de diferentes docentes, maior tempo na grade curricular e uso de estratégias facilitadoras do aprendizado. Busca-se, deta maneira, 
sensibilizar o acadêmico para o uso do BT em sua vida profissional, tornando-se um agente multiplicador dessa prática no cuidado à criança (Barreto, Maia, Depianti, Melo, Ohara, \& Ribeiro, 2017).

Quanto às dificuldades enfrentadas pelos profissionais entrevistados sobre a aplicação do BT na prática, além do conhecimento prévio insuficiente, já citado anteriormente, destaca-se a falta de oportunidades de capacitação, a desvalorização desta atividade pelos demais profissionais da equipe e o tempo insuficiente para realizá-lo, devido às inúmeras atribuições do enfermeiro. Estas dificuldades também são citadas em um artigo, no qual os autores também apontam a falta de material específico e de espaço adequado para realizar o BT (Marques, Silva, Cruz, \& Souza, 2015).

Outros estudos também relatam dificuldades semelhantes vivenciadas pelos enfermeiros, que comprometem a aplicação do BT, enfatizando-se a necessidade de se discutir estratégias para superá-las junto a estes profissionais e a instâncias administrativas das instituições (Oliveira, Maia, Borba, \& Ribeiro, 2015; Malaquias, Baena, Campos, Moreira, Baldissera, \& Higarashi, 2014).

Destaca-se a necessidade de se organizar capacitações sobre o brinquedo/ BT para os profissionais, possibilitando que protocolos assistenciais já existentes sejam realmente implementados na sistematização da assistência de enfermagem (Oliveira, Maia, Borba, \& Ribeiro, 2015).

Em relação ao uso do BT desde o momento da admissão da criança no hospital, os enfermeiros entrevistados reconhecem-no como um fator facilitador da assistência, reduzindo o estresse e o trauma relacionado à hospitalizada. Para eles, o BT ainda é pouco usado durante a admissão hospitalar na instituição onde atuam, acreditando que a elaboração de protocolos, que já estão em fase de produção, poderá contribuir para tornar esta prática uma realidade nos próximos anos.

Ressalta-se que o BT deve ser empregado em qualquer situação de cuidado, sempre que a criança necessite. Constata-se que a resposta é positiva e satisfatória, tanto em relação ao comportamento da criança, como para o profissional, ao facilitar a realização do procedimento durante a assistência de enfermagem (Malaquias, Baena, Campos, Moreira, Baldissera, \& Higarashi, 2014). 


\section{CONSIDERAÇÕES FINAIS}

Ao refletir sobre suas experiências com o uso do BT, o enfermeiro o considera como uma atividade complexa e trabalhosa, quando começa a aplicá-lo na prática, passando a identificar muitas vantagens ao utilizá-lo. Aponta, ainda, alguns fatores que dificultam a sua realização, entretanto, reconhece o seu potencial para envolver ainda mais a família no cuidado da criança hospitalizada e entende que seu uso deve ser rotineiro, acontecendo desde o momento da admissão da criança no hospital.

Nessa perspectiva, acredita-se que os resultados deste estudo podem sensibilizar os profissionais de saúde sobre a aplicação do BT em diferentes momentos da assistência, mas principalmente na admissão da criança no hospital, como forma de amenizar o estresse e humanizar o cuidado.

Considerando que o presente estudo foi realizado em um local onde o BT vem sendo utilizado com frequência pelos profissionais, recomenda-se a realização de outras pesquisas que permitam comparar esses resultados com os de instituições que ainda não utilizam o BT rotineiramente no seu cotidiano.

O uso da modalidade de investigação qualitativa, neste estudo, possibilitou explorar com a profundidade necessária, a maneira como o enfermeiro percebe o uso do BT, a partir de suas experiências no cuidado à criança hospitalizada. Evidenciou-se, mais uma vez, o potencial deste tipo de abordagem metodológica para abordar, de forma mais abrangente, questões de pesquisa desta natureza, que envolvem percepções e experiências de vida.

\section{REFERÊNCIAS}

Bardin, L. (2011). Análise de conteúdo. 6 ed. rev. e atual. Traduzido por Luís Antero Reto e Augusto Pinheiro. São Paulo, SP: Edições 70.

Barreto, L. M. S. C., Maia, E. B. S., Depianti, J. R. B., Melo, L. L., Ohara, C. V. S., \& Ribeiro, C. A. (2017). Giving meaning to the teaching of therapeutic play: the experience of nursing students. Escola Anna Nery, 21(2): e-20170038. Recuperado em 26 de abril de 2018 de http://www.scielo.br/pdf/ean/v21n2/en_1414-8145ean-21-02-e20170038.pdf

Barroso, M. C., Santos, R. S., Santos, A. E., Nunes, M. D., \& Lucas, E. A. (2020). Percepção das crianças acerca da punção venosa por meio do brinquedo terapêutico. Acta Paul Enferm., 33, e-APE20180296. Recuperado em 24 de abril de 2020 de http://www.scielo.br/pdf/ape/v33/1982-0194-ape-33-eAPE20180296.pdf

Caleffi, C. C. F., Rocha, P. K., Anders, J. C., Souza, A. I. J., Burciaga, V. B., \& Serapião, L. S. (2016). Contribuição do brinquedo terapêutico estruturado em um modelo de cuidado de enfermagem para crianças hospitalizadas. Rev Gaúcha Enferm., 37(2), e58131. Recuperado em 25 de abril de 2020 de http://www.scielo.br/pdf/rgenf/v37n2/0102-6933-rgenf-1983-144720160258131.pdf 
Conselho Federal de Enfermagem. (2017). Resolução COFEN n. 546, de 9 de maio de 2017. Dispõe sobre a utilização da técnica do Brinquedo/Brinquedo Terapêutico pelo Enfermeiro na assistência à criança hospitalizada. Brasília (DF): Diário Oficial da União. Recuperado em 01 de março de 2020 de http://www.cofen.gov.br/resolucao-cofen-no-05462017_52036.html

Conselho Regional de Enfermagem. (2004). Resolução COFEN n.295, de 24 de outubro de 2004. Dispõe sobre a utilização da técnica do Brinquedo/Brinquedo Terapêutico pelo Enfermeiro na assistência a criança hospitalizada. São Paulo (SP): COFEN. recuperado em 25 de abril de 2020 de http://www.corenro.org.br/resolucao-cofen-2952004_2087.html

Fontes C. M. B., Oliveira A. S. S, \& Toso L. A. (2017). Therapeutic toy in pediatric intensive therapy unit. Rev Enferm UFPE, 11(Supl.7), 2907-15. Recuperado em 26 de abril de 2018, de https://periodicos.ufpe.br/revistas/revistaenfermagem/article/download/9518/19200

La Banca, R. O., Ribeiro, C. A., Freitas, M. S., Freitas, M. A. O., Nascimento, L. C., Monteiro, O. O., et al. (2019). Brinquedo Terapêutico no ensino da insulinoterapia a crianças com diabetes: estudo de caso qualitativo. Rev. Eletr. Enferm. [Internet]; 21, 52591. Recuperado em 24 de abril de 2020, de https://doi.org/10.5216/ree.v21.52591.

Maia, E. B., Ribeiro, C. A., \& Borba, R. I. (2011). Compreendendo a sensibilização do enfermeiro para o uso do brinquedo terapêutico na prática assistencial à criança. Revista da Escola de Enfermagem da USP, 45(4), 839-46. Recuperado em 25 de abril de 2020, de http://www.scielo.br/pdf/reeusp/v45n4/v45n4a07.pdf

Maia, E. B. S., Ohara, C. V. S., Ribeiro, C. A. (2019). Ensino do brinquedo terapêutico na graduação em enfermagem: ações e estratégias didáticas utilizadas por professores. Texto Contexto Enferm [Internet], 28, e20170364. Recuperado em 25 de abrilde 2020, de https://dx.doi.org/10.1590/1980-265X-TCE-20170364

Malaquias, T. S. M., Baena, J. A., Campos, A. P. S., Moreira, S. R. K, Baldissera, V. D. A., \& Higarashi, I. H. (2014). O uso do brinquedo durante a hospitalização infantil: saberes e práticas da equipe de enfermagem. Ciencia, Cuidado e Saude, 13(1), 97-103. Recuperado em 25 de abril de 2020, de http://periodicos.uem.br/ojs/index.php/CiencCuidSaude/article/view/21802

Marques, D. K. A., Silva, B. L. K., Cruz, D. S., \& Souza, I. V. (2015). Benefícios da aplicação do brinquedo terapêutico: visão dos enfermeiros de um hospital infantil. Arquivos de Ciências da Saúde, 22(1), 64-68. $\begin{array}{lllllll}\text { Recuperado em } & 25 & \text { de } & \text { abril }\end{array}$ http://www.cienciasdasaude.famerp.br/index.php/racs/article/view/240/102

Ministério da Saúde. (2013). Resolução n. 466, de 12 de dezembro de 2012. Diretrizes e normas regulamentadoras de pesquisas envolvendo seres humanos. Brasília, DF: Ministério da Saúde. Recuperado em 25 de abril de https://bvsms.saude.gov.br/bvs/saudelegis/cns/2013/res0466_12_12_2012.html

Oliveira, C. S., Maia, E. B., Borba, R. I. H. \& Ribeiro, C. A. (2015). Brinquedo Terapêutico na assistência à criança: percepção de enfermeiros das unidades pediátricas de um hospital universitário. Revista da Sociedade Brasileira de Enfermagem Pediátrica, 15(1), 21-30. Recuperado em 25 de abril de 2020, de https://sobep.org.br/revista/images/stories/pdf-revista/vol15-n1/vol_15_n_2-artigo-de-pesquisa-3.pdf

Paladino, C. M., Carvalho, R., \& Almeida, F. A. (2014) Brinquedo terapêutico no preparo para a cirurgia: comportamentos de pré-escolares no período transoperatório. Revista da Escola de Enfermagem da USP, 48(3), 423-9. Recuperado em 25 de abril de 2020, de http://www.scielo.br/pdf/reeusp/v48n3/pt_0080-6234reeusp-48-03-423.pdf

Polit, D. F. \& Beck, C. T. (2011). Fundamentos de pesquisa em enfermagem: avaliação de evidências para a prática de enfermagem. 7 ed. São Paulo, SP: Artmed.

Pontes, J. E., Tabet, E., Folkmann, M. A. S., Cunha, M. L. R., \& Almeida, F. A. (2015). Therapeutic play: preparing the child for the vaccine. Einstein (São Paulo), 13(2), 238-242. Recuperado em 25 de abril de 2020, de http://www.scielo.br/pdf/eins/v13n2/pt_1679-4508-eins-13-2-0238.pdf 